\title{
Síndrome diencefálico en un niño con desnutrición crónica e hiperactividad
} Diencephalic syndrome in a child with chronic malnutrition and hyperactivity

\author{
Dra. Florencia Palmieria, Dr. Ignacio Núñeza, Dra. María V. Falcón ${ }^{a}$, Dr. Nicolás Fortini Cabarcos ${ }^{a}$, \\ Dr. Ariel Cheistwer ${ }^{a}$ Dra. Lorena Mirón ${ }^{a}$ y Dr. Emilio Martínez Iriart ${ }^{a}$
}

\section{RESUMEN}

El síndrome diencefálico es una causa infrecuente de desnutrición. Se produce por la disfunción del hipotálamoy está asociado a tumores del encéfalo. Los pacientes presentan una gravey progresiva pérdida de peso, aunque el apetitoy la ingesta calórica son, por logeneral, adecuados. Característicamente, los síntomas neurológicos son tardíos, lo que retrasa la sospecha diagnóstica.

Se presenta a un paciente de 2 años y 6 meses de edad con desnutrición crónica grado II, derivado con diagnóstico presuntivo de enfermedad celíaca con mala adherencia y fracaso del tratamiento. Durante la internación, se arribó al diagnóstico de síndrome diencefálico secundario a un astrocitoma pilocítico grado I.

Palabras clave: desnutrición, síndrome diencefálico, astrocitoma pilocítico.

\begin{abstract}
Diencephalic syndrome is an infrequent cause of malnutrition. It is produced by a malfunctioning hypothalamus, and it is related to encephalic tumors. Patients present a serious and progressive weight loss although the appetite and calorie intake are, usually, adequate. Neurological symptoms typically have a late appearance, delaying diagnostic suspicion.

We present a patient aged 2 years and a half with grade II chronic malnutrition, referred with presumptive diagnosis of celiac disease, with poor adherence and treatment failure. During hospitalization, diagnosis of diencephalic syndrome secondary to grade I pilocytic astrocytoma was reached.

Key words: malnutrition, diencephalic syndrome, pilocytic astrocytoma.
\end{abstract}

http:/ / dx.doi.org/10.5546/ aap.2018.e667

Cómo citar: Palmieri F, Núñez I, Falcón MV, et al. Síndrome diencefálico en un niño con desnutrición crónica e hiperactividad. Arch Argent Pediatr 2018;116(5):e667-e670.

a. Unidad 6 de Clínica Pediátrica, Hospital de Niños R. Gutiérrez, Ciudad de Buenos Aires.

Correspondencia:

Dr. Ignacio Núñez: ignacio_25@hotmail.com

Financiamiento: Ninguno.

Conflicto de intereses: Ninguno que declarar.

Recibido: $12-12-2017$

Aceptado: 26-4-2018

\section{INTRODUCCIÓN}

El síndrome diencefálico (SD), síndrome de Russell o caquexia de Russell fue descrito por A. Russell en $1951 .^{1}$ Se produce por la disfunción del hipotálamo y está asociado a tumores del encéfalo. Se caracteriza por una marcada emaciación con ingesta calórica adecuada, levemente disminuida o, rara vez, aumentada, ${ }^{2}$ con llamativa conservación de la talla y el perímetro cefálico. La asociación con hiperactividad es muy frecuente..$^{3-7}$ Los signos neurológicos no suelen estar presentes en los primeros meses de evolución y, en caso de encontrarse, los más frecuentes son los oftalmológicos $(50 \%)$-nistagmus, alteración del campo visual y palidez de papila- ${ }^{6,8}$ seguidos por cefalea y vómitos. ${ }^{4}$

\section{CASO CLÍNICO}

Paciente de sexo masculino de 2 años y 6 meses de edad, procedente de Paraguay, que consultó por la pérdida importante de peso de cinco meses de evolución, mala actitud alimentaria, hiperactividad y vómitos aislados.

Presentaba diagnóstico presuntivo de enfermedad celíaca a partir de anticuerpos inmunoglobulina $\mathrm{G}(\mathrm{IgG})$ e inmunoglobulina A (IgA) antigliadina positivos, con anticuerpos antiendomisio y antitransglutaminasa negativos, realizados en su país de origen. Se encontraba en tratamiento con dieta libre de gluten, con mal cumplimiento.

Al ingresar, se lo evaluó de buen ánimo, hiperactivo y con buena actitud ante el juego; en contraposición con una marcada desnutrición, escaso tejido subcutáneo, piel fláccida, abdomen levemente excavado y nalgas en bolsa de tabaco (Figura 1). Su desarrollo neuromadurativo era acorde a la edad y sus signos vitales se hallaban dentro de los límites normales. Valores antropométricos al ingresar: peso de $9,500 \mathrm{~kg}$ (percentilo $<3$; puntaje z: $-2,56$ ); índice de masa corporal (IMC): 12 (percentilo < 3/ puntaje z: -3 ); talla: $89,5 \mathrm{~cm}$ (percentilo 25); perímetro cefálico: 49,5 cm (percentilo 50-75); y peso/edad: $72 \%$; 
desnutrición grado II según la clasificación de Gómez; adecuación peso/talla: $74 \%$, que correspondía, según la clasificación de Waterloo, a una desnutrición moderada (o déficit de un $26 \%$ ). Se negaba a la ingesta, principalmente,

FIGURA 1. Grado de emaciación del paciente, con nalgas en bolsa de tabaco

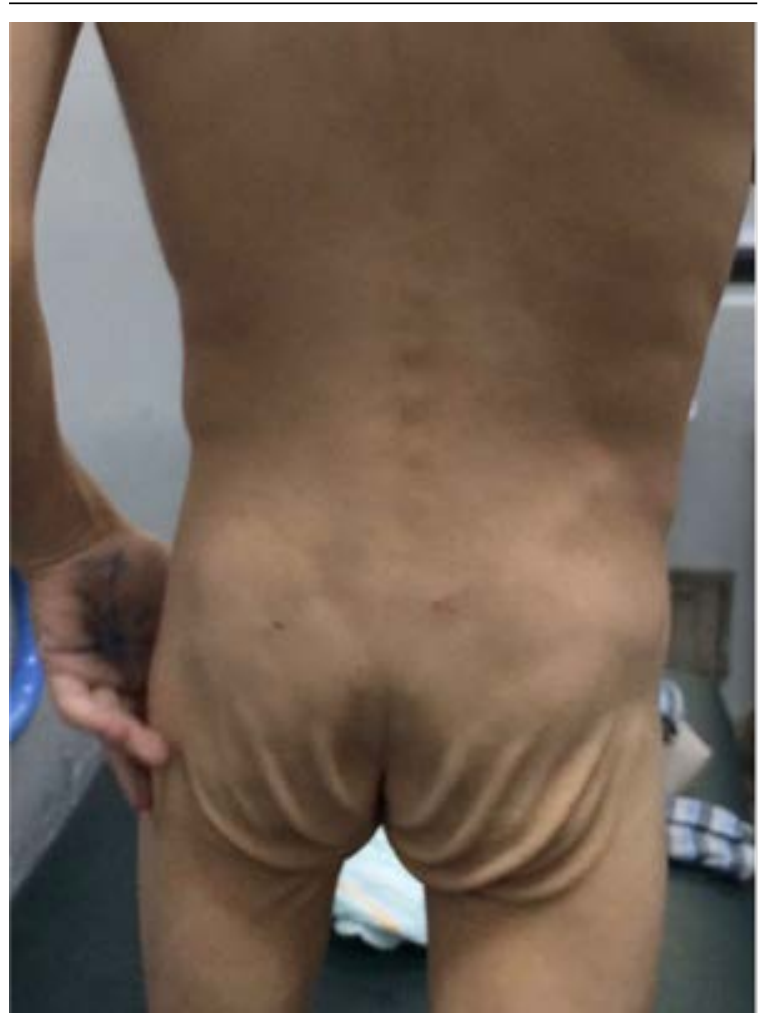

de alimentos sólidos y semisólidos, asociado a diarrea y vómitos ocasionales.

Los estudios de laboratorio realizados al ingresar y en el transcurso de la internación fueron normales e incluyeron evaluación hematológica, función renal y hepática, albúmina, amonio, ácido láctico y función tiroidea. Se descartaron causas malabsortivas, con estudio funcional de materia fecal normal. Fueron negativos los anticuerpos antiendomisio IgG e IgA, y los anticuerpos antitransglutaminasa. La IgA total estaba dentro de los límites normales. Se descartaron causas infectológicas, con serologías negativas para virus de la inmunodeficiencia humana (VIH), virus de la hepatitis $B(\mathrm{VHB})$, virus de la hepatitis C (VHC), toxoplasmosis, Chagas y sífilis.

No se evidenciaron trastornos deglutorios ni alteraciones estructurales del aparato digestivo superior luego de la evaluación por medio de la seriada esófago-gastroduodenal y video-deglución.

La madre y el niño fueron evaluados por el equipo de salud mental y se excluyeron causas psicoafectivas a través de las entrevistas periódicas y la evaluación del juego.

Se indicó la alimentación por vía enteral con gastroclisis continua con leche hidrolizada. Se incrementó su aporte calórico diario hasta llegar a $140 \mathrm{cal} / \mathrm{kg} /$ día en su octavo día de internación y se complementó con una dieta hipercalórica (tasa metabólica basal: $208 \mathrm{kcal} / \mathrm{kg}$ ). El paciente evolucionó, durante los primeros 14 días, con un aumento de peso de $62 \mathrm{~g} /$ día y presentó un vómito diario, predominantemente matinal y, en ocasiones, de abundante cuantía.

FIGURA 2. Resonancia magnética nuclear del sistema nervioso central, de corte sagital y axial, que evidencia una lesión ocupante de espacio en la región selar con edema perilesional y dilatación de los ventrículos laterales, sin desviación de la linea media
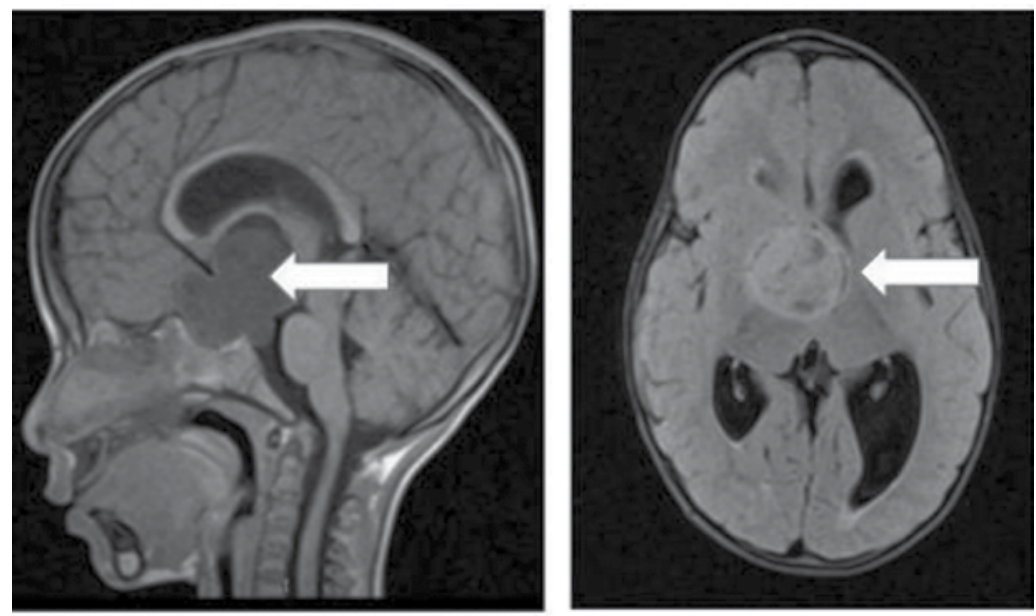
A las 2 semanas, por la normalidad de los estudios citados anteriormente y el patrón de vómitos observados ante la alimentación enteral, se decidió realizar una resonancia magnética nuclear (RMN) (Figura 2) y una tomografía axial computada (TAC) del sistema nervioso central (SNC). En dichos estudios, se evidenció una imagen ocupante de espacio en la región selar que se reforzó con la administración de gadolinio, con extensión hacia la región subfrontal y cisterna prepontina que invadió el tercer ventrículo, el seno cavernoso derecho, el quiasma óptico y las ramas del polígono de Willis. A estos hallazgos se asociaba la dilatación de ambos ventrículos laterales y la compresión talámica por la masa tumoral. No se realizó inicialmente una RMN de la médula espinal. Se efectuó exéresis tumoral macroscópicamente completa, con diagnóstico anatomopatológico de astrocitoma pilocítico de bajo grado. ${ }^{11}$

\section{Evolución}

Luego de la realización de imágenes del SNC, en las que se constató hidrocefalia secundaria a la lesión ocupante de espacio, se colocó una válvula de derivación ventrículo-peritoneal. Después de la exéresis tumoral, el paciente presentó diabetes insípida con requerimientos de desmopresina reglada, hipotiroidismo medicado con levotiroxina, disautonomías en los miembros inferiores y disminución de la agudeza visual (alteraciones que persisten hasta la actualidad) y también alteraciones transitorias del ritmo sueño-vigilia e hipertermia central, diagnosticadas luego de haber descartado la patología infecciosa. Evolucionó con hiperorexia con posterior incremento de peso (peso al egreso, 50 días después de la cirugía, de $14,120 \mathrm{~kg}$ -PC 50-75-) (Figura 3), por lo que se modificó su dieta a normocalórica.

Actualmente, han pasado 10 meses desde el diagnóstico. El paciente regresó a su país de origen y se presentó en el Hospital para los controles periódicos en los Servicios de Oncología y Neurocirugía. De forma ambulatoria, ha realizado RMN de la columna y el cerebro sin evidencia de recaída. Por tratarse de un glioma de bajo grado, con exéresis macroscópicamente completa, y por la morbilidad asociada, no realizó quimioterapia ni radioterapia. Realiza el seguimiento clínico y con estudios de imágenes.

\section{DISCUSIÓN}

El SD es una causa infrecuente de desnutrición, por lo que los reportes son esporádicos y las series estudiadas hacen referencia a un escaso número de pacientes.

Se presenta, por lo general, con ingesta normal, levemente disminuida ${ }^{4} \mathrm{o}$, rara vez, aumentada. ${ }^{2}$ En el caso del paciente citado, el hallazgo distintivo fue la negativa a la ingesta, a pesar del grado de desnutrición.

La edad media de comienzo del compromiso nutricional es, aproximadamente, a los 7 meses de vida, y la edad media de diagnóstico es a los 18 meses. ${ }^{4,9}$ Los artículos consultados refieren una mayor gravedad del cuadro clínico cuanto menor es la edad del paciente al momento del hallazgo. ${ }^{10}$

Otra de las características llamativas del paciente fue la normalidad de los estudios de laboratorio nutricionales, metabólicos, hematológicos y endocrinológicos, coincidentes con lo encontrado en la bibliografía. ${ }^{4}$

Se desconocen con certeza los mecanismos asociados a la emaciación, pero las hipótesis incluyen niveles elevados de hormona de crecimiento (HC) con respuesta paradojal a la carga de glucosa, ${ }^{4,5,7-9}$ resistencia parcial a la acción de la HC y aumento de la secreción de $\beta$-lipotropina (péptido lipolítico), que resulta

FIgURA 3. Recuperación nutricional del paciente 45 días después de la exéresis tumoral

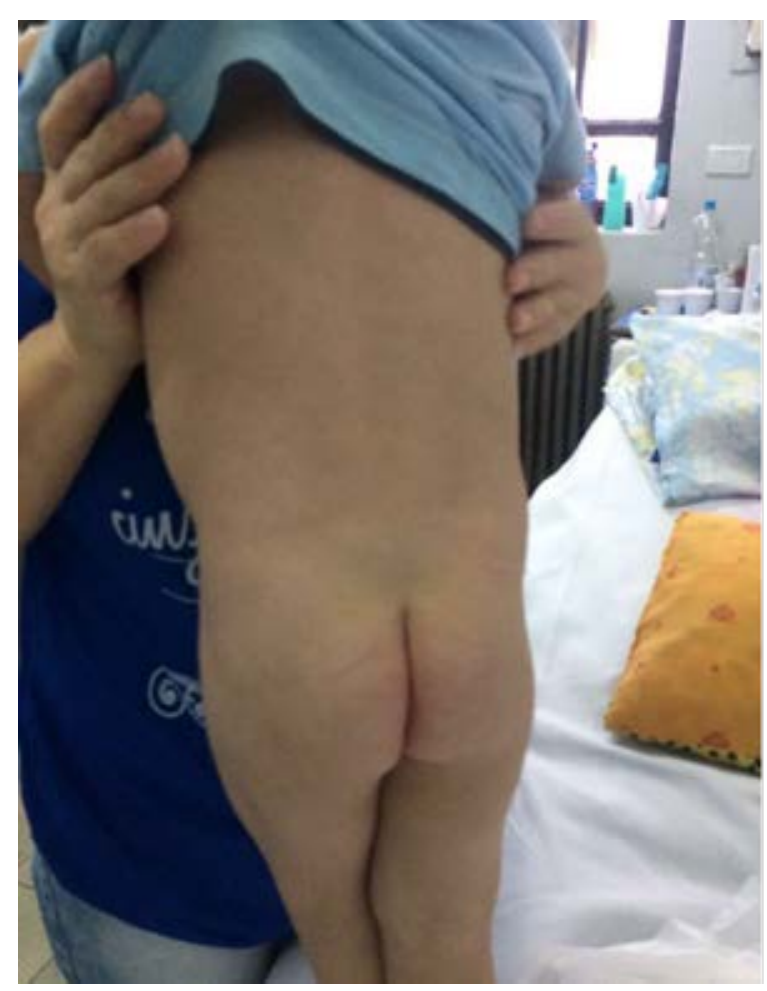


en el incremento de la lipólisis con consecuente

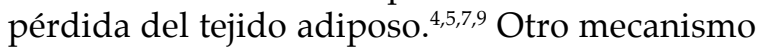
descrito es la desregulación en la liberación de leptina y grelina,, 3 ambas asociadas al mecanismo de apetito y saciedad.

En lo que respecta a los síntomas neurológicos, al ingresar, el paciente presentaba un examen neurológico normal, coincidente con otros reportes de casos. Durante la internación, evolucionó con vómitos matinales como único síntoma de hipertensión endocraneana.

Los tumores más frecuentemente encontrados corresponden a astrocitomas pilocíticos grado $\mathrm{I}^{11}$ localizados en el área hipotálamo-quiasma óptico. ${ }^{3,4,6,7}$ También se ha descrito su asociación con astrocitomas cerebelosos, ependimomas supraselares, espongioblastomas supraselares y tumores talámicos. ${ }^{8}$

Por causas aún no establecidas, el SD solo afecta al 20\% de los pacientes con tumores localizados en esta región. Su asociación con SD los hace más agresivos y de peor pronóstico. ${ }^{9,10}$

El tratamiento varía según los autores, con diferentes combinaciones de cirugía, radioterapia y quimioterapia..$^{3-5,10}$ En el caso de los gliomas de bajo grado, es de elección la escisión completa, que, muchas veces, no se puede realizar por la ubicación del tumor. ${ }^{5}$ Permite lograr la resolución de los síntomas, pero suele asociarse a efectos adversos neurológicos y endocrinológicos. ${ }^{3} \mathrm{La}$ radioterapia fue el tratamiento principal hasta la década de los ochenta, del Siglo XX, cuando perdió lugar por sus efectos adversos, sobre todo, en lactantes. ${ }^{4,5}$ Stival y Lucchesi citan que pueden obtenerse buenos resultados combinando bajas dosis de etopósido y cisplatino, con baja mielo y neurotoxicidad. ${ }^{3}$

Sin tratamiento, la supervivencia es de 6 meses a 2 años. ${ }^{2,5,10}$

En síntesis, la desnutrición secundaria obliga a descartar un amplio espectro de patologías orgánicas y psicoafectivas, y se debe evaluar cuidadosamente la oportunidad de cada intervención diagnóstica o terapéutica.
Si bien el SD es una rara causa de desnutrición crónica, se debe solicitar una neuroimagen en pacientes con emaciación, a pesar de una ingesta calórica normal, disminuida o aumentada, asociada con hiperactividad, en ausencia de síntomas neurológicos, una vez descartadas las causas más frecuentes.

\section{REFERENCIAS}

1. Russell A. A diencephalic syndrome of emaciation in infancy and childhood. Arch Dis Child1951; 26:274.

2. Aguilar Moliner I, Costa Orvay JA, Juma K, etal. Astrocitoma de vías ópticas: una causa infrecuente de retraso ponderal en el lactante. An Pediatr (Barc) 2007; 66(6):622-4.

3. Stival A, Lucchesi M, Farina $S$, et al. An infant with hyperalertness, hyperkinesis, and failure to thrive: a rare diencephalic syndrome due to hypothalamic anaplastic astrocytoma. BMC Cancer 2015; 15:616.

4. Kim A, Moon JS, Yang HR, et al. Diencephalic syndrome: a frequently neglected cause of failure to thrive in infants. Korean J Pediatr 2015; 58(1):28-32.

5. Moreno Villares JM, FernándezCarriónF, Gallego Fernández $\mathrm{ME}$, et al. Síndrome diencefálico: una causa poco común de malnutrición. An Pediatr (Barc) 2002; 56(2):466-71.

6. Gamstorp I, Kjellman B, Palmgren B. Diencephalic Syndromes of Infancy: Report of 3 Children with Emaciation Syndrome and Disproportionately Large Hands and Feet. J Pediatr 1967; 70(3):383-90.

7. Velasco P, Clemente M, Lorite R, et al. The Role of Leptin in Diencephalic Syndrome. Pediatrics 2014; 133(1):e263-6.

8. Poussaint TN, Barnes PD, Nichols K, et al. Diencephalic Syndrome: Clinical Features and Imaging Findings. AJNR Am J Neuroradiol 1997; 18(8):1499-505.

9. Fleischman A, Brue C, Poussaint TY, et al. Diencephalic Syndrome: A Cause of Failure to Thrive and a Model of Partial Growth Hormone Resistance. Pediatrics 2005; 115(6);e742-8.

10. Báez Segurola L, Jiménez García R, Piñeiro Fernández E, et al. Síndrome diencefálico como causa de desnutrición severa. Rev Cubana Pediatr 2013; 85(1):120-9.

11. Louis D, Perry A, Reifenberger G, et al. The 2016 World Health Organization Classification of Tumor of the Central Nervous System. Acta Neutropathol 2016; 131(6):803-20.

12. ChipkevitchE, Fernandes A. Hypothalamictumor associated with atypical forms of anorexia nervosa and diencephalic syndrome. Arq Neuropsiquiatr 1993; 51(2):270-4.

13. Pires ME, Maranhão-Filho PA. Síndrome Diencefálica: Síndrome de Russel. Rev Bras Neurol 2010; 46(1):37.

14. Uher R, Treasure J. Brain lesions and eating disorders. J Neurol Neurosurg Psychiatry 2005; 76(6):852-7.

15. Gómez Santos F. Desnutrición. Bol Med Hosp Infant Mex $1946 ; 3(4): 543-51$. 